\title{
УДК 655.3.066.51
}

\section{АНАЛІТИЧНІ ДОСЛІДЖЕННЯ ТЕХНОЛОГІЇ ДРУКУ ОБ'СМНИХ ЗОБРАЖЕНЬ}

\author{
I. М. Назар, М. С. Мартинюк, О. Р. Назар \\ Українська академія друкарства, \\ вул. Під Голоском, 19, Львів, 79020, Украӥна
}

Поліграфія відіграє важливу роль у розвитку суспільства. Через необхідність передачі інформації виник інтенсивний розвиток засобів та методів виготовлення друкованої продукиії; існує постійний пошук нових, удосконалення наявних технологій, устаткування та осучаснення методів передавання інформаџії. Підвищені вимоги до якості та захисту друкованої продукиії зумовили інтенсивний розвиток новітніх технологій, в основі яких найновімі досягнення з різних галузей науки $i$ техніки.

Відомо, щзо лентикулярний друк можна застосовувати для захисту друкованої продукиії від підробки. Наприклад, якщчо на виробі буде так звана лінзова картинка, то ие значно ускладнить його підробку. Також иее зображення можна розглядати як оригінальну частину дизайну друкованої продукиї, яка буде привертати увагу спожсивачів та вирізняти виріб від іншої друкованої продукиї.

Відомо, щзо стереограми, або тривимірні приховані зображення, рекомендують людям, які багато працюють з документацією чи за комп'ютером, а також тим, у кого професійна діяльність потребує неперервного напруження очей. Оскільки у прачівників офісів робота потребує постійного фокусування на ближніх об'єктах, $i$ зазвичай розслаблення очних м'язів шляхом переведення погляду на більш віддалені предмети не відбувається, то розглядання стереограм укріплює очні м'язи і допомагає зберегти гостроту зору. Також спеціалісти зазначають, щзо внаслідок розглядання стереограм значно покращується кровообіг ділянок мозку, які відповідають за злагоджену роботу півкуль. Розглядання лінзових картинок називають спортом для очей.

Проаналізовано технологічний процес виготовлення об' ємних зображень з використанням класичних та новітніх технологій лентикулярного друку. На основі здійсненого аналізу створено класифікацію об'ємних зображень за видом основи, призначенням, оптичними ефектами і технологією виготовлення.

Ключові слова: тривимірні зображення, календарі, лентикулярний друк, захист продукиії, паковання, лентикулярні лінзи, стереограми, ичифровий друк.

Постановка проблеми. Невпинний розвиток засобів комунікації та індустрії маркетингу зумовлює пошук доступних та надійних поліграфічних технологій. Досліджено технології виготовлення об'ємних зображень, встановлено, що для ïx створення широко використовуються класичні та новітні технології. Тому i 
виникла потреба в аналізі історії, призначенні об’ємних зображень, їх класифікації та сферах застосування.

Мета статті - проаналізувати технологічний процес виготовлення об’ємних зображень з використанням класичних та новітніх поліграфічних технологій. На основі опрацьованих літературних джерел навести класифікацію об'ємних зображень.

Виклад основного матеріалу дослідження. Як відомо, історія тривимірних зображень датована 1833 р., коли Чальз Вітстон намалював два простих ескізи, на яких були зображені дві відмінні перспективи. Вітстон спробував їх розглядати через пристрій, який складався з дзеркал та рухомих площин. Дзеркала допомагали, з'єднуючи два рисунки, розглядати їх об'ємно. Подальший розвиток така ідея отримала після винайдення фотографії. У 1850 р. було винайдено портативний пристрій для перегляду стереоскопічних фотографій. Винахідником стереограм вважають Крістофера Тайлера, який взяв за основу своїх пошуків дослідження відомого ученого Бела Юлеша. Поштовхом до винаходу Тайлера стало припущення про можливість знайти спосіб створення двох зображень, зберігши при цьому тривимірність. Ефект комп'ютерної стереографії на основі одного зображення відомий 3 60-х років. Масове виробництво стереограм розпочалось в Японії у 70-х роках минулого століття. 31990 р. вони стають популярними спочатку в США, а потім і в усьому світі.

Зазначимо, що тема лентикулярного друку в Україні протягом останніх років не розвивається. Зауважимо, що закордоном цей ринок вимірюється мільйонами доларів, наприклад в Японії - 100 млн доларів, в США - 250 100 млн доларів, в Європі - 200 млн доларів (згідно з даними компанії Grapac Japan).

Лентикулярна технологія базується на оптичному ефекті та особливостях людського зору, отриманні об'ємного та рухомого зображення за допомогою лентикулярних плівок. Найпростіший спосіб полягає у скеруванні погляду крізь площину рисунка. Необхідно дивитись за зображення, не фокусуючи погляд. Другий спосіб більш складний — перехресний погляд, при цьому лінії прицілювання очей перетинаються на деякій відстані перед зображенням, але водночас фокусуються на його поверхні. Фон починає подаватися вперед, тривимірне зображення виглядає як об'ємний рисунок [4].

Для створення стереограм розроблено низку простих програм-генераторів. Перш ніж створити зображення, необхідно підготувати два рисунки: один фактурний та однорідний - фоновий, другий контрастний - для проявлення тривимірного зображення. Наступний крок - комп'ютерна обробка за допомогою спеціального програмного забезпечення та створення кодованого зображення. Для того щоб отримати стерео- і варіопродукцію, необхідно розмістити на зворотному боці аркуша лентикулярного пластику закодоване плоске зображення. Розрізняють два способи:

- друк зображення класичним способом та прикріплення за допомогою ламінації аркуша пластику. Такий спосіб є доволі трудомістким, оскільки потребує точного суміщення вручну віддрукованого зображення з мікроскопічними лінзами 


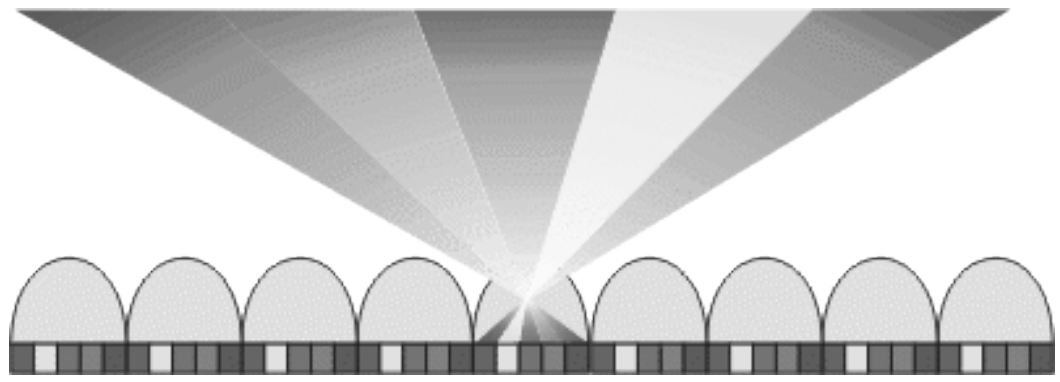

Рис. 1. Принцип утворення стереозображення за допомогою лентикулярної лінзи

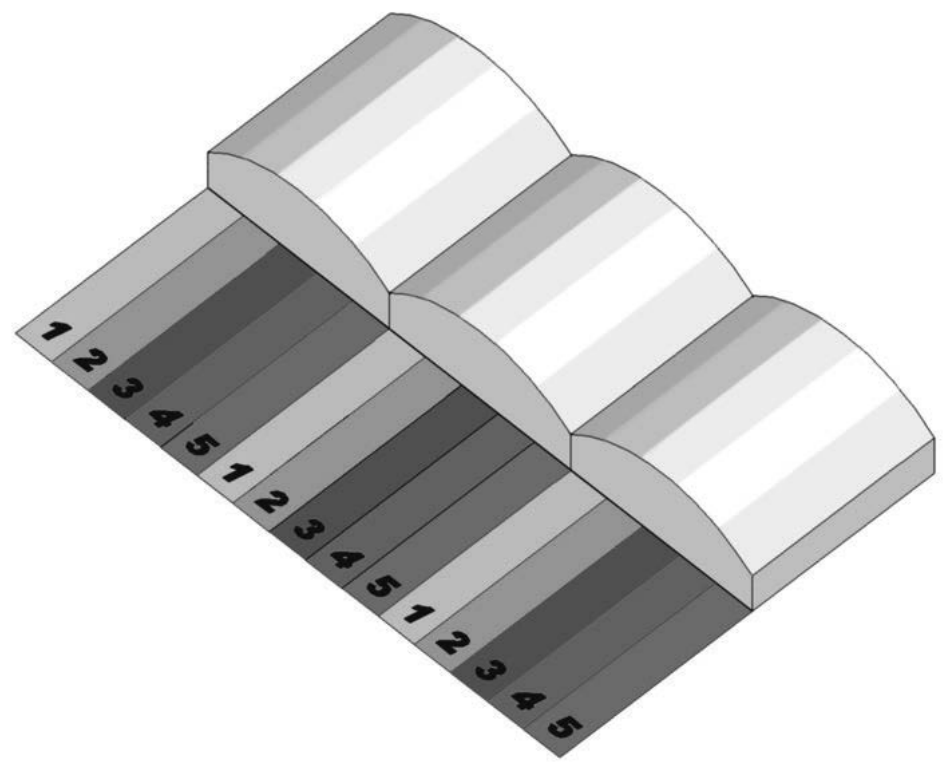

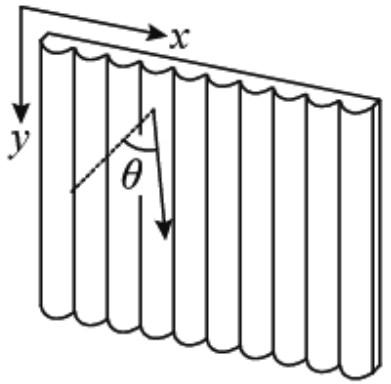

(a)

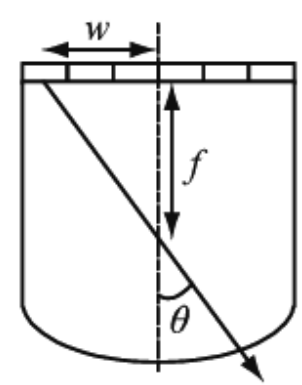

(b)

Рис. 2. Геометричні параметри для лентикулярної лінзи 

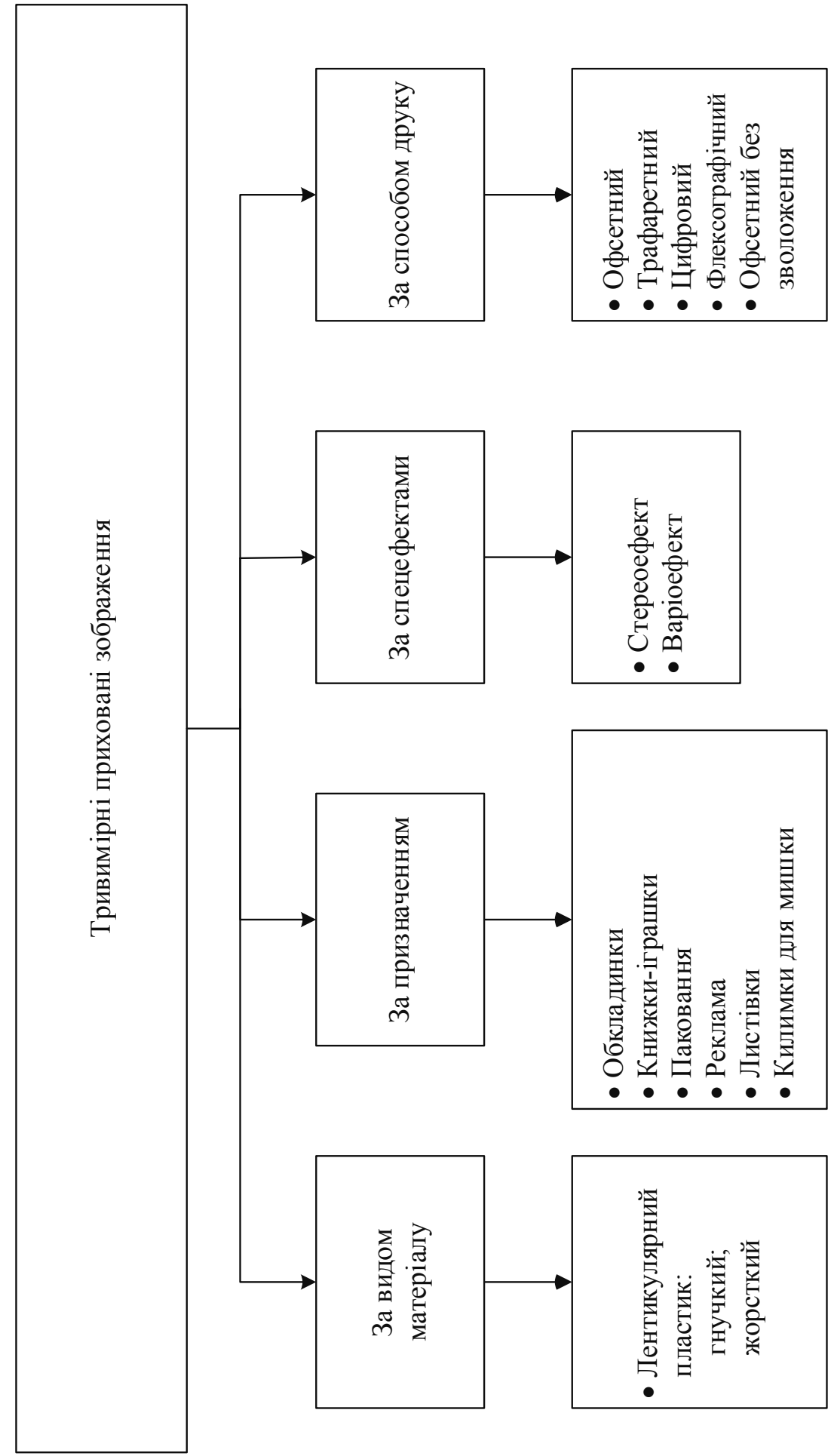

菊

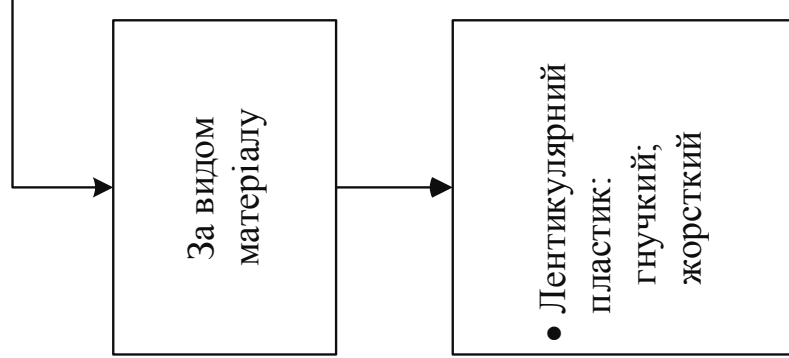


пластику. Його прийнято використовувати для виготовлення невеликих накладів, оскільки помилка на частку міліметра може призвести до випуску бракованої продукції;

- зображення наносять безпосередньо на зворотний бік пластику. Такий спосіб зазвичай використовують для виготовлення лентикулярної продукції великими накладами. Використовують офсетний спосіб друку із зволоженням або без зволоження, флексографічний, трафаретний чи цифрові способи друку [6].

Для друкування на лентикулярному пластику використовують УФ-затверджувальні фарби. Фарби повинні відштовхуватись силіконовим шаром форми, їхня внутрішня когезія має перевищувати адгезію до цього шару і менше реагувати на зміну температури. Необхідно, щоб друкарська машина була з холодним способом закріплення шару фарби на відбитку і розміщувалась після кожної друкарської секції, оскільки після гарячої сушарки пластик може деформуватись або помутніти [2].

Після друку зображення на відбитку залишається прозорим. Це не дає змоги отримати кінцевий результат — необхідний стерео- чи варіоефект. Тому необхідно на задруковане зображення нанести шар криючих білил чи ламінувати його папером, маширувати картоном, фольгувати зі зворотного боку, щоб позбутись ефекту непрозорості.

Готові вироби з аркуша отримують за допомогою технологічної операції вирубки стандартним чи індивідуально розробленим штампом. Зазвичай розміри готових виробів невеликі. Для виробів з тонкого пластику рекомендують обмежитись форматом А6 (максимально - форматом А4).

Розрізняють два види лентикулярного пластику:

- тонкий або гнучкий;

- товстий або жорсткий.

Тонкий пластик товщиною до 1 мм має більшу частоту лінзового растра (60200 лінз/дюйм) і використовується під час виготовлення малоформатної продукції. Для виготовлення великоформатної продукції застосовують товстий пластик завтовшки від 1 до 4 мм. Частота лінзового растра такого пластику - 10-60 лінз/дюйм. Як матеріал для пластику використовують поліетилентерефталат-гліколь (поліефірне скло) або аморфний поліетилентерефталат. Товстий пластик для зовнішнього застосування виготовляють із акрилату або полікарбонату, які мають достатню вологостійкість та стійкість до УФ-випромінювання $[1,9]$.

Аналіз та класифікацію об'ємних зображень здійснювали на основі вивчення джерел науково-технічної інформації - підручники і навчально-методичні посібники, часописи, зокрема «КомьюАрт», «Print Plus», інтернет-сайти та рекламні матеріали фірм виробників і постачальних матеріалів для лентикулярного друку $[2-5,8]$.

Висновки. Проаналізовано технологічний процес виготовлення об'ємних зображень 3 використанням класичних та новітніх технологій лентикулярного друку. На основі здійсненого аналізу створено класифікацію об'ємних зображень за видом основи, призначенням, оптичними ефектами і технологією виготовлення. 


\section{СПИСОК ВИКОРИСТАНИХ ДЖЕРЕЛ}

1. Lenticular Printing: and the Brave New World of 3D Printing. URL: http://printbrain. webmartuk.com/print-technology/lenticular-printing-and-the-brave-new-world-of-3dprinting/.

2. Запоточний В. Й. Технології захисту цінних паперів : навч. посіб. Львів : Видавництво Львівської політехніки, 2013. 149 с.

3. Киппхан Г. Энциклопедия по печатным средствам информации. Технологии и способы производства / пер. с нем. Москва : МДУД, 2003. 1280 с.

4. Назаркевич Є. Особливості способів друку та технологій виготовлення стерео-варіо зображень. Вісник книжкової палати. 2013. № 7. С. 1-4.

5. Plastic lenticular technology limited. URL: http: //www.plasticlenticular.com/.

6. Lenticular Printing: Using LightField Data and Halftone Screening for improved 3D Prints. URL: http://lightfield-forum.com/2012/08/lenticular-printing-using-lightfield-data-and-halftone-screening-for-improved-3d-prints/.

7. Yamazaki H., Takaki Y. Printing 3D light field with 1D halftone screening. URL: https://www. semanticscholar.org/paper/Printing-3D-light-field-with-1D-halftone-screening-YamazakiTakaki/c330da4d666d96355884c01a1c4ba859bb10fc0d.

8. Ткаченко В. П., Манаков В. П., Шевчук А. В. Оперативні та спеціальні види друку: технологія, обладнання : навч. посіб. Харків, 2005. 334 с.

9. Dancy A. Lenticular Printing 101: Incorporate Motion Print on Your Next Project. URL: https://1 touchpoint.com/blog/lenticular-printing-101-incorporate-motion-print-on-your-nextproject.

\section{REFERENCES}

1. Lenticular Printing: and the Brave New World of 3D Printing. Retrieved from http:// printbrain.webmartuk.com/print-technology/lenticular-printing-and-the-brave-new-worldof-3d-printing/ (in English).

2. Zapotochnyi, V. Y. (2013). Tekhnolohii zakhystu tsinnykh paperiv. Lviv : Vydavnytstvo Lvivskoi politekhniky (in Ukrainian).

3. Kippkhan, G. (2003). Entciklopediia po pechatnym sredstvam informatcii. Tekhnologii i sposoby proizvodstva / per. s nem. Moskva : MDUD (in Russian).

4. Nazarkevych, Ye. (2013). Osoblyvosti sposobiv druku ta tekhnolohii vyhotovlennia stereovario zobrazhen: Visnyk knyzhkovoi palaty, 7, 1-4 (in Ukrainian).

5. Plastic lenticular technology limited. Retrieved from http: //www.plasticlenticular.com/ (in English).

6. Lenticular Printing: Using LightField Data and Halftone Screening for improved 3D Prints. Retrieved from http://lightfield-forum.com/2012/08/lenticular-printing-using-lightfield-dataand-halftone-screening-for-improved-3d-prints/ (in English).

7. Yamazaki, H., \& Takaki, Y. Printing 3D light field with 1D halftone screening. Retrieved from https:/www.semanticscholar.org/paper/Printing-3D-light-field-with-1D-halftone-screeningYamazaki-Takaki/c330da4d666d96355884c01a1c4ba859bb10fc0d (in English).

8. Tkachenko, V. P., Manakov, V. P., \& Shevchuk, A. V. (2005). Operatyvni ta spetsialni vydy druku: tekhnolohiia, obladnannia. Kharkiv (in Ukrainian). 
9. Dancy, A. Lenticular Printing 101: Incorporate Motion Print on Your Next Project. Retrieved from https://1touchpoint.com/blog/lenticular-printing-101-incorporate-motion-print-onyour-next-project (in English).

doi: 10.32403/2411-3611-2019-2-36-45-51

\title{
ANALYTICAL RESEARCH OF VOLUME IMAGES PRINTING TECHNOLOGY
}

\author{
I. M. Nazar, M. S. Martyniuk, O. R. Nazar \\ Ukrainian Academy of Printing, \\ 19, Pid Holoskom St., Lviv, 79020, Ukraine \\ inazarlviv@gmail.com,m_mart@meta.ua
}

Lenticular printing technology is an old technique, which enables stereoscopic $3 D$ by recording pictures taken by two or more cameras onto one medium. It is often awkward in its transition between insufficient images due to sparse sampling from the light space. In this paper, we suggest a method for making $3 D$ print which reproduces light space represented as a light field by introducing an ideal halftone screening.

Lenticular films produce special flip (animation/stereo), motion, morphing (transformation) and 3D effects. The lenticular images are used for high-end products such as magazine covers, packaging, cases for CDs, DVDs etc., mouse pads, postcards and luxury packaging.

Printing on lenticular films requires a high level of process know-how. As well as a comprehensive knowledge of the UV printing process, special prepress and material know-how is required. High register accuracy is also needed, as even minute differences can lead to undesirable effects in the lenticular image.

In the adjacent application, the laterally reversed image is printed onto the smooth reverse side of a lenticular film. The process colors are applied first using UV printing and a full-area UV opaque white is then added. Finally, a full-area protective UV gloss coating is applied.

The article analyzes the technological process of making volumetric images using classic and advanced lenticular printing technologies. Based on the performed analysis, the classification of three-dimensional images by type of basis, purpose, optical effects and manufacturing technology has been formed.

Keywords: three-dimensional images, calendars, lenticular printing technology, product protection, packaging, lenticular lenses, stereograms, digital printing technology. 